DOI: $10.14451 / 2.135 .7$

\title{
ГЕНЕЗИС РАЗВИТИЯ CLAUSULA REBUS SIC STANTIBUS В РОССИЙСКОЙ ЦИВИЛИСТИЧЕСКОЙ ДОКТРИНЕ
}

\author{
(c) 2019 Понька Виктор Федорович \\ доктор юридических наук, профессор кафедры гражданского права, процесса \\ и международного частного права юридического института \\ Российский университет дружбы народов, Россия, Москва \\ Email:Vf_Ponka@mail.com
}

В рамках данной статьи осуществляется анализ развития института clausula rebus sic stantibus, включая исследование его основных черт и сущностных характеристик. Автором проводится соотношение существенного изменения обстоятельств и невозможности исполнения. В результате проведенного исследования, делается вывод о том, что clausula rebus sic stantibus обладает рядом конститутивных признаков, таких как: непредвиденность, непреодолимость, чрезмерность обстоятельств и пр.

Ключевые слова: договор, изменение договора, расторженрие договора, невозможность исполнения обязательств

Говоря о значении исследуемой темы, следует отметить, что современное право развивается в условиях оказываемых на него различных объективно-обусловленных факторов, отражающих закономерности развития гражданско-правового оборота.

Гражданско-правовой оборот, подобно живой материи, находится в постоянном развитии, на которое оказывают влияние его участники, путем проявления своих интересов, а в контексте последних реализации своих прав.

В условиях такого развития меняются и подходы к правовому регулированию частноправовых отношений. Так был потеснен один из фундаментальных принципов частного права - pacta sunt servanda, лежащий не только в основе обеспечения и гарантии договорной дисциплины, но и выступающий своего рода гарантом стабильности экономических отношений. Участие в гражданском обороте сопряжено с различными рисками, в том числе с рисками изменения обстоятельств, которые участники гражданско-правового оборота не могли предвидеть в момент заключения договора.

Указанные обстоятельства привели к необходимости возникновения новой доктрины, учения которой было положены в основу принципа clausula rebus sic stantibus, который наряду с pacta sunt servanda явился гарантом стабильности, обусловленной недопущением нарушения еще одного из основополагающих принципов частного права, а именно, равенства сторон, вы- ражающимся в данном случае соблюдении баланса имущественных интересов [1].

Стоит отметить, что возможность изменения или расторжения договора участниками гражданско-правового оборота при существенном изменении обстоятельств ни в коем случае не умоляет значение pacta sunt servanda. В действительности речь идет о модификации указанного принципа исходя из объективных требований развития гражданско-правового оборота.

Согласно п. 1. ст. 452 Гражданского кодекса РФ существенное изменение обстоятельств, из которых стороны исходили при заключении договора, является основанием для его изменения или расторжения, если иное не предусмотрено договором или не вытекает из его существа.

При этом, добавляет кодекс во втором абзаце указанной статьи «изменение обстоятельств признается существенным, когда они изменились настолько, что, если бы стороны могли это разумно предвидеть, договор вообще не был бы ими заключен или был бы заключен на значительно отличающихся условиях» [2].

Если обратиться к лингвистическому исследованию понятия «существенные обстоятельства», то согласно толковому словарю С.И. Ожегова и Н.Ю.Шведовой под ними следует понимать «самую сущность, существо чего-нибудь, крайне важное для чего-нибудь по своей принципиальности, первостепенности» [3].

Практически из одноименных воззрений, но облеченных в юридический окрас, подходит к 
этому вопросу и толковый словарь по гражданскому праву, который под существенными обстоятельствами понимает «возникшие внезапно, после заключения договора, без участия, вины и вне контроля сторон непредвиденные и непреодолимые обстоятельства, которые не могли быть разумно учтены сторонами при заключении договора и риск наступления которых не был принят на себя сторонами. Данные обстоятельства приводят к существенной затруднительности, а именно существенным образом изменяют равновесие договорных обязательств в силу либо возрастания для стороны стоимости исполнения, либо уменьшения ценности полученного стороной исполнения, и (или) бессмысленности исполнения договора» [4].

Понятие существенного изменения обстоятельств отечественному правопорядку было известно еще в дореволюционной России.

Так, К.П. Победоносцев в своей работе, посвященной исследованию гражданского права, указывал на то, что «понятие о вине и ответственность за неисполнение устраняются, когда причиною невыполнения было обстоятельство внешнее, не зависевшее от личной воли и сделавшее исполнение... юридически невозможным...» [5].

В указанный период выделялись лишь единичные случаи освобождения от исполнения обязанностей по договору в отсутствие объективной возможности для исполнения [6]. Так, в частности, отмечалось, что «вступившие в договор не могут самопроизвольно уклоняться от исполнения принятых на себя обязанностей; но каждая из договорившихся сторон не лишена права просить суд о приостановлении действия договора по таким обстоятельствам, которые разрушают состоявшееся между контрагентами соглашение, так, напр., по несуществованию предмета договора или заблуждению или обману относительно его существенного качества» [7].

Стоит отметить, что обстоятельства, которые могли оказать влияние на юридический эффект договора, связанные с возможностью его изменения или вовсе прекращением были известны и советской цивилистической доктрине. Так, согласно ст. 144Гражданского кодекса РСФС 1922 г., «если в двустороннем договоре исполнение стало невозможным для одной из сторон вследствие обстоятельства, за которое ни она, ни другая сторона не отвечает, она при отсутствии в законе или договоре иных постановлений не вправе требовать от другой стороны удовлетворения по договору. При возникновении таких обстоятельств каждая из сторон была вправе требовать от контрагента только возврата всего, что она исполнила, не получив соответствующего встречного удовлетворения» [8].

В Гражданском кодексе РСФСР 1964 года институт расторжения договора в связи с существенно изменившимися обстоятельствами не получил должного развития. Только несколько положений, содержащиеся в Гражданском кодексе РСФСР предусматривали вопросы, связанные с прекращением обязательств в следствие изменения плана и в связи с невозможностью исполнения.

Так, согласно ст.234 Гражданского кодекса РСФСР «обязательство между социалистическими организациями подлежит прекращению или изменению сторонами в установленном порядке в случаях, когда акты планирования народного хозяйства, на которых обязательство основано, изменены распоряжением, обязательным для обеих сторон» [9].

Или же согласно ст.235 Гражданского кодекса РСФСР «обязательство прекращается невозможностью исполнения, если она вызвана обстоятельством, за которое должник не отвечает» [10].

Весьма показательным представляется описание механизма реализации института существенного изменения обстоятельств советским цивилистом В.К. Райхером, который сравнил институт существенного изменения обстоятельств с проводом «по которому струится правовая энергия, находясь под сильным воздействием «внешних факторов»..., которые искривляют траекторию движения правовой энергии, нарушая имущественную эквивалентность... в целях устранения возникшего дисбаланса между сторонами и существует механизм, позволяющий... расторгнуть договор либо... внести в него изменения» [11].

Не смотря на метафоричность высказывания В.К. Райхер, описывая обстоятельства, имеющие существенное значение, все же выявил главный их конститутивный признак - если отношения не прекратить или изменить, то этот приведет к нарушению баланса между сторонами.

Исследуя правовую природу института существенного изменения обстоятельств Е.А. Суханов пришел к выводу о том, что расторжение или изменение договора в связи с существенным изменением обстоятельств это особый 
случай, под которым следует понимать такие события не зависящие от сторон, наступление которых не могло быть предвидено сторонами, а если бы стороны могли их предвидеть, договор вообще не был бы ими заключен или был бы заключен на совершенно иных условиях, отличающихся от тех, которые они согласовали в момент заключения договора. При этом, отмечает ученый, здесь важное значение приобретает цель, которой предопределяется изменение либо прекращение договорного обязательства, а именно обеспечение восстановления баланса интересов сторон договора, существенным образом нарушенного в силу непредвиденного изменения внешних обстоятельств, не зависящих от их воли [12].

При этом, необходимо отметить, что явления, события, факты, которые можно квалифицировать в качестве существенных обстоятельств может определить только суд при рассмотрении и разрешении дела с учетом оценки имеющих значение различных факторов.

Е.А. Контратьева, занимаясь концептуальным исследованием содержания существенного изменения обстоятельств пришла к выводу о существовании нескольких подходов, тем самым сформировав в след за ними различные концепции, в частности: концепцию «форс-мажора» и концепцию «затруднений» [13].

Концепция «форс-мажора» характеризуется отсутствием всякой возможности исполнения гражданско-правовых обязательств. При этом, невозможность может быть обусловлена как субъективными факторами так и объективными. В основе объективных факторов лежат объективно-обусловленные обстоятельства, очевидно препятствующие исполнению, например, цунами, землетрясение и пр. Субъективные факторы связаны со стороной договора - физическим лицом, например, потеря его здоровья, выражающегося в тяжелой форме инвалидности, делающей невозможным исполнить договор.

В своем исследовании ученый также выделяет длящуюся и временную невозможность. Длящаяся невозможность является основанием для полного неисполнения обязательств, а временная невозможность приводит к просрочке исполнения должником его обязательств. При таких условиях, в случае длительного срока существования обстоятельств, препятствующих исполнению договора, стороны могут отказаться от него, тем самым расторгнув его. В тех случаях, когда речь о временных затруднениях исполнения гражданско-правового договора, то договор подлежит изменению, например, в связи с пролонгацией ряда его условий [14].

С учетом сказанного, наличие различных подходов к проблеме возникновения обстоятельств, имеющих существенное значение, говорит о гибкости концепции clausula rebus sic stantibus, главной целью которой является обеспечение баланса интересов между сторонами, основанного на принципах равенства и справедливости.

С другой стороны, такое количество подходов к вопросу о существенно изменившихся обстоятельств продиктовано отсутствием четких критериев оценки изменившихся обстоятельств в самом законе. Отсутствие в законе даже приблизительных ориентиров, позволяющих контрагентам самим оценить значительность изменений, по сути, лишает их возможности самостоятельно урегулировать данную проблему и всякий раз требует обращение в юрисдикционный орган.

Вне всякого сомнения концептуальный подход Е.А. Кондратьевой обогатил науку гражданского права, однако на взгляд автора, представляется необходимым более строго считаться с используемой в гражданском праве терминологией, в особенности, тогда, когда исследователь уравнивает в своих юридических значениях обстоятельства, имеющие существенное значение, с невозможностью исполнения или с обстоятельствами непреодолимой силы, как это красноречиво демонстрирует Е.А. Кондратьева в разработанной ею концепции «форс-мажора», тогда как указанные институты подчиняются совершенно различным юридическим целям и ставят перед собой различные задачи.

Интересной в научном плане также представляется трактовка существенного изменения обстоятельств В.С. Петрищевым, который в своем исследовании пришел к выводу, что «под существенным изменением обстоятельств чаще всего понимает вмешательство государства в гражданский оборот. А именно: принятие нормативного правового акта, прекращение или уменьшение бюджетного финансирования, судебное решение. Все эти обстоятельства имеют юридическую природу» [15]. При этом стоит отметить, что автор помимо юридической характеристики существенного обстоятельства, дает им еще и экономическую оценку. 
Как утверждает В.С. Петрищев к существенно изменившимся обстоятельствам, носящим экономический характер, следует относить достаточно широкий круг обстоятельств тесно связанных с рынком, товарно-денежными отношениями.

При этом под экономическими отношениями в контексте суждений ученого понимается предпринимательская деятельность, связанная с отчуждением товаров, выполняем работ, оказанием услуг; деятельность хозяйствующих субъектов, которые занимают доминирующее положение на соответствующих рынках и пр.

При этом, как отмечает исследователь, «обстоятельства носят сложно доказуемый характер. Характер каждого изменения обстоятельств определяет суд при рассмотрении и разрешении дела. Заинтересованная сторона должна доказать, что те обстоятельства, на которые она ссылается, соответствуют ст. 451 ГК и дают основания для расторжения либо изменения договора. В этом отношении у формально-юридических трактовок оснований определения существенно изменившихся обстоятельств перед экономическими в плане доказывания есть определенные преимущества» [16].

Например, утверждает В.С. Петрищев «не требуется доказывать, что «юридическое» изменение произошло вне зависимости от воли сторон; нормативно-правовой акт и судебные решения принимают органы публичной власти, независимо, во всяком случае, юридически, от участников оборота...» [17].

При экономическом критерии существенного изменения обстоятельств возникает проблема определения факторов, обладающие свойствами экономических процессов. Что может служить такими факторами? Может ли служить динамика изменения курса рубля по отношении к известным валютам? Будет ли оказывать влияние на существенность обстоятельств финансовый кризис? И прочие обстоятельства, которые повлияли на имущественный интерес стороны или сторон. Именно на данные вопросы и должен ответить рассматривая дело орган судебной власти.

Показательным в научном плане к существенному изменению обстоятельств представляется подход Очхаева Т.Г. Ученый полагает, что «признание и применение на практике учения clausula rebus sic stantibus является общераспространенной тенденцией и должно подчиняться определенным условиям» [18]. Вслед за исследователь конструирует определенные признаки существенно изменившихся обстоятельств.

Во-первых, существенное изменение обстоятельств имеет место после заключения договоpa;

во-вторых, произошедшее событие должно выходить за рамки квалификации в качестве события нормальной хозяйственной деятельности; должно носить исключительный характер.

в-третьих, произошедшее событие должно носить явно обременительный характер для стороны, на которой лежит обязанность исполнить договор;

в-четвертых, наступление обстоятельств должно быть непредвидимым;

в-пятых, риск существенного изменения обстоятельств не может быть возложен на сторону договора [19].

Как неоднократно замечали ученые исследуя смысл положений ст. 451 Гражданского кодекс Российской Федерации для того чтобы прийти к правильным выводом необходимо заручиться пониманием о том, что смысл учений о существенно изменении обстоятельств заключается в «ограничении необоснованного вмешательства во взаимоотношения участников договора, создании гарантийной стабильности договорных связей, восстановлении справедливости и недопущении возникновения кабальных отношений вследствие неудачного стечения обстоятельств в случаях, когда это действительно необходимо» [20].

Следует отметить, что признаки существенно изменившихся обстоятельств находят свое отражение в Гражданском кодексе Российской Федерации.

Так, согласно ст. 451 Гражданского кодекса РФ для того, чтобы какое-либо изменение обстоятельств было отнесено к категории существенных, требуется наличие ряда определенных условий, а именно:

во-первых, существенно изменившиеся обстоятельства не могли быть предвидены сторонами, заключенного гражданско-правового договора;

во-вторых, существенно изменившиеся обстоятельства должны быть непреодолимы сторонами гражданско-правового договора;

в-третьих, существенно изменившиеся обстоятельства должны носить характер чрезмерных обстоятельств; 
в-четвертых, ни обычай делового оборота, ни существо договора не предполагают необходимости возложения риска происшедшего изменения обстоятельств на заинтересованную сторону [21].

Говоря о применении норм института существенного изменения обстоятельств, следует отметить, что суд не всегда допускает необходимость расторгнуть договор ввиду наступления описанных выше обстоятельств. В нашей стране полагаем обусловлено это причинами поддержания правоприменительными органами правового и экономического порядка. Поскольку если суды будут часто расторгать договоры ввиду существенно изменившихся обстоятельств, то это может привести к дестабилизации экономических отношений путем создания условий, при которых большая часть субъектов предпринимательских отношений воспользуется своим правом, что негативно скажется не только в отношении контрагента предпринимателя, но и всего гражданского общества в целом, так как приведет к перебоям в его работе. Поэтому суды не занимали позицию слабой стороны при неоднократном повышении, например, курса основных валют - евро, доллара, по отношению к рублю, в том числе при возникновении финансовых кризисов, всякий раз списывая неудачи предпринимателей не на наступившие события, а на так называемые предпринимательские риски и критерии разумности, т.е. допускаемое предпринимателем предвидение подобных обстоятельств, исходя из практики совершения им постоянных деловых операций.

Изменение же гражданско-правового договора в связи с существенным изменением обстоятельств согласно п. 4 ст. 451 Гражданского кодекса Российской Федерации допускается по решению суда только в исключительных случаях. Например, когда расторжение договора противоречит общественным интересам. Или, когда расторжение договора повлечет для сторон ущерб, значительно превышающий затраты, необходимые для исполнения договора на измененных судом условиях [22].

Подводя итог проведенному исследованию, синтезируя различные концептуальные подходы к существенно изменившимся обстоятельствам, следует отметить, что расторжение либо изменение договора в связи с возникновением таких обстоятельств представляет собой самостоятельный случай прекращения, либо измене- ния договорных обязательств. Следует отметить, что красной нитью, конструирующей юридическую сущность исследуемых обстоятельств является цель, которой предопределяется изменение либо прекращение договорного обязательства, а именно необходимость восстановления баланса интересов сторон договора, существенным образом нарушенного в силу непредвиденного изменения внешних обстоятельств, не зависящих от их воли.

Однако как уже ранее отмечалось, чтобы какое-либо изменение обстоятельств, связанных с конкретным договором, было отнесено к категории существенных требуется одновременное наличие предусмотренных законом условий. Поэтому большая часть обстоятельств, на первый взгляд подходящих под внешнее описание признаков такого условия не могли быть отнесены в качестве существенных обстоятельств виду несоблюдения формально-юридического подхода.

Пожалуй, одним из главнейших условий применения норм о существенных обстоятельствах является то, что стороны при заключении договора исходили из того, что такого изменения обстоятельств не произойдет. То есть, иными словами, отсутствие фактора прозорливости субъекта гражданско-правовых отношений и служит решающим признаком квалификации таких обстоятельств в качестве существенных.

Следует обратить внимание на то, что определение понятия непредвидимость сторонами было дано в одном из гражданско-правовых дел, согласно которому «обстоятельства являются заведомо непредвиденными для каждой из сторон если они непреодолимы и чрезмерны и когда ни обычай делового оборота, ни существо договора не предполагают необходимости возложения риска произошедшего изменения обстоятельств на заинтересованную сторону. При этом, причины возникновения данных обстоятельств лежат за пределами действий контрагентов и вследствие этого от них не зависят» [23].

Отмечается, что в законе используется конструкция «разумное предвидение» в момент заключения гражданско-правового договора.

Собственно разумность, как добросовестность и справедливость, относится к так называемым оценочным понятиям, допускающим известную свободу правоприменителя в их интерпретации с учетом конкретных обстоятельств при рассмотрении и разрешении граж- 
данско-правового спора, возникшего между сторонами.

В плане дефиниции разумности показательно определение В.С.Ема, который под разумностью понимает «осмысленность (рациональность), логичность и целесообразность поведения субъекта. Разумным можно считать поведение субъекта, если оно является результатом осмысления социально-экономической обстановки, в которой он находится, логически вытекает из нее и целесообразно для него» [24].

Решающим фактором в оценке изменения обстоятельств будет ответ на вопрос, могли ли стороны разумно предвидеть обстоятельства в момент заключения договора. К примеру, заключая договор аренды недвижимого имущества и определяя стоимость арендных платежей в долларах США по курсу Центрального банка на день осуществления платежа, стороны, действующие разумно, не могли не предвидеть возникновение экономических обстоятельств, приведших к обвалу рубля и существенному повышению цены договора. Подобным образом могут оцениваться и иные чрезвычайные изменения условий имущественного оборота, например кратковременное многократное увеличение ставки рефинансирования, возникновение гиперинфляции и т.д.

Дальнейшее исследование обстоятельств, имеющих существенное значение, приводит к мысли о том, что изменение обстоятельств должно быть вызвано причинами, которые заинтересованная сторона была не в состоянии преодолеть после их возникновения при той степени заботливости и осмотрительности, какая от нее требовалась по характеру договора и условиям оборота.

Стоит обратить внимание на используемые в законе очередные эфемерные конструкции «заботливость» и «осмотрительность», приводящие к очередному судейскому усмотрению при их определении.

Толкование нормы, предусмотренной в ст.451 Гражданского кодекса РФ в части проявления заботливости и осмотрительности позволяет одному из ученых сделать следующие выводы: «нарушение соотношения имущественных интересов сторон является следствием сложной причинно-следственной связи, поскольку изменение обстоятельств, служащее основанием для изменения или расторжения договора,- результат определенных юридических фактов, кото- рые сторона договора не могла преодолеть при той степени заботливости и осмотрительности, какая от нее требовалась по характеру договора и условиям оборота. Невозможность преодолеть указанные причины является критерием оценки причин, вызывающих изменение обстоятельств...» [25].

Дальнейшее исследование правовой природы существенно изменившихся обстоятельств, связано с соотношением имущественных интересов сторон, поскольку исполнение договора при наличии существенно изменившихся обстоятельств без соответствующего изменения его условий нарушило бы имущественные интересы стороны. А это означает, что сторона, которая рассчитывала на социально-экономический эффект от заключения договора в значительной степени лишилась бы того, на что была вправе рассчитывать.

Важное значение при этом имеет понимание самого интереса, т.е. того, что сторона лишится при возникновении обстоятельств. При этом стоит заметить, что интерес сопряжен не только с получением соответствующих материальных благ, но и тесно связан с неким моральным удовлетворением стороны.

Изучение интереса известно российской цивилистики. Наибольше вклад в исследование данной категории права, как нам представляется, сделал В.П. Грибанов.

Так, по мнению классика российской цивилистики в юридической литературе понятие «интерес» употребляется в различных значениях. Интерес - это сочетание объективного и субъективного моментов. С субъективной точки зрения интерес представляет собой целенаправленность мыслей и действий, отражающих материальные и духовные потребности отдельных людей (личный интерес), социальных групп и исторических общностей. Объективный характер интереса состоит прежде всего в том, что он не только плод нашего разума, не только результат человеческого сознания, а есть реально существующее в жизни явление, которое необходимо учитывать и с которым нельзя не считаться, ибо интересы, двигают жизнью народов» [26].

Учет интересов сторон договора играет очень важную роль, поскольку именно интерес соответствующих субъектов договорных отношений оправдывает их возникновение и ожидание исполнения с целью получения задуманного результата. 
И в последних на что стоит обратить внимание при исследовании правовой природы обстоятельств, имеющих существенное значение, - это понятие риска, поскольку из обычаев или существа договора не вытекает, что риск изменения обстоятельств несет заинтересованная сторона.

Полагаем, что указанный признак наиболее обстоятельно можно проиллюстрировать одним из примеров судебной практики.

Суть рассматриваемого дела сводилась к следующему: гражданка Российской Федерации Новоселова П.С. обратилась в суд с иском к банку о внесении изменений в кредитный договор, заключенный между сторонами в 2013 году в иностранной валюте (евро), установив денежное обязательство в рублях Российской Федерации по курсу евро, действующему на момент выдачи кредита. В обоснование иска Новоселова П.С. указала, что с момента заключения сделки существенно изменился установленный Банком России курс евро, чего при заключении кредитного договора стороны предвидеть не могли, в связи с чем исполнение обязательств на изменившихся условиях представляется крайне затруднительным.

Банк мотивировал свою позицию тем, что согласно закону заемщик обязан возвратить заимодавцу то же количество денег, определенное в той же валюте, или других вещей, определенных родовыми признаками, которое им было получено при заключении договора займа, а если иное не предусмотрено законом или договором, также уплатить проценты на эту сумму.

Суд, проанализировав доводы сторон, установил, что при заключении договора стороны добровольно пришли к соглашению о займе в иностранной валюте.

Таким образом, возврат суммы займа должен быть произведен исходя из валюты займа, указанной в договоре, то есть в размере полученной при заключении договора суммы с учетом уплаты процентов.

Увеличение выраженных в рублях платежей должника по кредитному договору вследствие повышения курса валюты долга не свидетельствует об изменении установленного договором соотношения имущественных интересов сторон, в связи с чем изменение курса иностранной валюты по отношению к рублю нельзя расценивать как существенное изменение обстоятельств, являющееся основанием для изменения договора в соответствии со ст. 451 ГК РФ [27].

\section{Библиографический список}

1. Посохов С.П., Елисеева В.В. Становление и развитие института Clausula rebus sic stantibus. Евразийский юридический журнал. № 5 (132) 2019. СС. 196-197

2. Гражданский кодекс Российской Федерации (часть первая) от 30.11.1994 № 51-ФЗ// Российская газета, № 238-239, 08.12.1994.

3. Ожегов С.И., Шведова Н.Ю. Толковый словарь русского языка. Издательство «Азъ», 1992 год.

4. Толковый словарь гражданского права. Ч. 1. Сер. «Юридические толковые словари». М.: Городец, 2006. С.С. 417-418

5. Победоносцев К.П. Курс гражданского права: В 3 т. / Под ред. В.А. Томсинова. Т. 3. М.: Зерцало, 2003. С. 150.

6. Чистяков К.Е. Изменение и расторжение гражданско-правового договора: диссертация на соискание ученой степени кандидата юридических наук. Томск, 2002. С. 92.

7. Тютрюмов И.М. Законы гражданские с разъяснениями Правительствующего Сената и комментариями русских юристов. Книга четвертая. М.: Статут, 2004. С. 81.

8. Гражданский Кодекс РСФСР 1922 года, введенный в действие Постановлением ВЦИК от 11 ноября 1922 года //СПС «Консультант Плюс».

9. Гражданский кодекс РСФСР, утв. ВС РСФСР 11.06.1964. Ведомости ВС РСФСР, 1964, N24, ст. 407.

10. Гражданский кодекс РСФСР, утв. ВС РСФСР 11.06.1964. Ведомости ВС РСФСР, 1964, N24, ст. 407.

11. Райхер В.К. Абсолютные и относительные права // Вестник гражданского права. 2007. N2. С.124.

12. Е.А. Суханов. Российское гражданское право: В 2 т. Обязательственное право: Учебник. Том 2. 2-е издание, стереотипное, «Статут», 2011 г. // СПС «Консультант Плюс».

13. Кондратьева Е.М. Концепции регулирования изменившихся обстоятельств во внешнеторговых сделках. Вестник Нижегородского университета им. Н.И. Лобачевского, 2014, № 5, СС. 96-101

14. Кондратьева Е.М. Указанное сочинение. С.97.

15. Петрищев В.С. Существенное изменение обстоятельств: правоприменение ст. 451 ГК РФ опыт стран общего и континентального права. ВШЭ. С.11. 
16. Петрищев В.С. Указанное сочинение. С.11.

17. Петрищев В.С. Указанное сочинение. С.12.

18. Очхаев Т.Г. Изменение и расторжение договора в связи с существенным изменением обстоятельств «Статут», 2017//СПС «Консультант Плюс».

19. Очхаев Т.Г. Указанное сочинение//СПС «Консультант Плюс».

20. Андреев С.Е. Договор. Заключение, изменение, расторжение. Москва, Проспект, 1997 год. С.С. 71-72.

21. Гражданский кодекс Российской Федерации (часть первая) от 30.11.1994 № 51-ФЗ// Российская газета, № 238-239, 08.12.1994.

22. Гражданский кодекс Российской Федерации (часть первая) от 30.11.1994 № 51-Ф3// Российская газета, № 238-239, 08.12.1994.

23. Постановление Федерального арбитражного суда Центрального округа от 29 января 2004 г. N A353794/03-С17// СПС «Консультант Плюс».

24. Ем В.С. Осуществление и защита гражданских прав // Гражданское право: Учебник / Под ред. Е.А. Суханова. М.: Волтерс Клувер, 2004. Т. 1. С. 531

25. Позднышева Е.В. Расторжение и изменение гражданско-правового договора: Монография, ИЗиСП, Москва, 2018// СПС «Консультант Плюс».

26. Грибанов В.П. Осуществление и защита гражданских прав. Классика российского правового наследия. Статут. 2001 г.// СПС «Консультант Плюс»

27. Обзор судебной практики Верховного Суда Российской Федерации N1, 2017 г.» (утв. Президиумом Верховного Суда РФ 16.02.2017) // СПС «Консультант Плюс». 